\title{
O ENSINO DE LÍNGUAS POR UMA ABORDAGEM COMPLEXA EM TEMPOS DE PANDEMIA: QUEBRANDO PARADIGMAS
}

\author{
Suzana Longo da Crur* \\ Diógenes Cândido de Lima ${ }^{* *}$ \\ Cremilton de Souza Santana ${ }^{* * *}$
}

RESUMO: Os desafios desencadeados pela pandemia da covid-19 que a Educação tem enfrentado globalmente têm fomentado reflexões sobre novas formas de ensinar e aprender no contexto escolar. Neste artigo, expomos o relato de experiência da condução do ensino de línguas dentro de uma abordagem complexa, que se deu no Ensino Médio de uma escola da rede pública por intermédio de ensino remoto, em um contexto imbuído de restrições de acesso à internet. O principal objetivo deste estudo consistiu em avaliar as possibilidades de alcance dessa abordagem, bem como seus pontos positivos e os obstáculos vivenciados. Por meio da análise desse processo, concluímos que é possível trabalhar a linguagem de forma efetiva dentro de uma perspectiva da complexidade, pois carrega os benefícios de um ensino multidimensional, não-linear, não-reducionista e transdisciplinar, o qual intenta incentivar a capacidade crítica do aluno, ao passo que trabalha fatores históricos, sociais, políticos, culturais e psicoemocionais, ensejando uma formação voltada para o sujeito integral, com atividades adequadas ao seu contexto e realidade atuais. Como obstáculos, presenciamos uma certa resistência de alguns alunos ao paradigma complexo de ensino-aprendizagem. O paradigma proposto estava embutido em um ensino que se apresentou de maneira não-fragmentada em disciplinas, e que, por ter um espectro maior de alcance e amplitude na abordagem dos temas propostos nas atividades requeria um posicionamento mais questionador e reflexivo por parte do aluno. Uma parcela desses alunos ainda demonstrou certo apego a uma visão mais cartesiana de se conceber o conhecimento, estando ainda enraizados aos processos tradicionais de ensino-aprendizagem.

PALAVRAS-CHAVE: Complexidade; Ensino de línguas; Ensino remoto; Formação integral; Transdisciplinaridade.

\section{Palavras iniciais}

O ano de 2020 iniciou-se, essencialmente, marcado pela complexidade e por incertezas devido à notícia de um novo vírus que teria iniciado na China e que poderia se alastrar ao redor do mundo. No entanto, ainda parecia estar distante de nós, brasileiros, pois os primeiros casos de infectados ocorreram em países na Europa e no Oriente-Médio. Assim, em fevereiro do mesmo ano, o primeiro caso de covid-19 foi registrado no Brasil e, pouco tempo depois, em março, as aulas foram suspensas no Distrito Federal, seguidas do decreto de distanciamento social, postulado pelo Governo de São Paulo, que serviu de exemplo para todos os outros estados e municípios brasileiros para tomarem suas próprias medidas.

Diante desse cenário, o ensino-aprendizagem nas escolas de todo o país também teve que se adaptar às novas medidas de segurança da Organização Mundial da Saúde (OMS), devido aos decretos postulados por instituições oficiais de todas as esferas sociais, seja no

\footnotetext{
* Mestre em Letras: Cultura, Educação e Linguagens pela Universidade Estadual do Sudoeste da Bahia (Uesb). ** Doutor em Curriculum and Instruction (Estudos da Linguagem) pela Southern Illinois University, at Carbondale - EUA (SIUC). Professor pleno da Universidade Estadual do Sudoeste da Bahia (Uesb). Realizou estágio de pós-doutoral na Florida International University, em Miami, na área de Linguística Aplicada.

*** Mestre em Letras: Cultura, Educação Linguagens pela Universidade Estadual do Sudoeste da Bahia (Uesb).
} 
âmbito municipal, estadual ou federal. Nesse sentido, a covid-19 trouxe inúmeras implicações para a sociedade e no contexto educacional não foi diferente, uma vez que novas alternativas de ensino e aprendizagem vêm sendo estabelecidas, sobretudo, as que consideram as particularidades da realidade social do público estudantil, pois a pandemia da Covid-19 tornou ainda mais visível as diversas desigualdades sociais no país. Por consequência, as escolas se viram diante da necessidade de se adequar a um contexto que tem demandado uma total reconfiguração no processo educacional.

Como expresso por Edgar Morin em várias de suas obras, qualquer reforma da educação deverá, antes de tudo, começar pela reforma dos próprios educadores e dos próprios alunos, pois sem o uso da criatividade, aptidão fundamental do sapiens-demens, nenhuma educação, nenhuma antropoética, nenhuma formação ou autoformação se faz possível (ALMEIDA; CARVALHO, 2009). Isso se encaixa perfeitamente nos tempos que vivemos atualmente, nos quais uma reconfiguração do ensino se faz premente, quando as instituições educacionais, professores e alunos têm se deparado com a necessidade de lidar com o processo de ensino-aprendizado de forma totalmente diversa e atípica.

Dessa forma, em um momento marcado por profunda instabilidade no contexto educacional, propomos neste estudo uma investigação a partir de nosso relato de experiência, sob os paradigmas qualitativo e etnográfico, para respondermos à seguinte questão: Quais os pontos positivos e quais obstáculos são encontrados ao trabalhar o ensino de línguas por meio de uma abordagem complexa no contexto do Ensino Médio de uma escola da rede pública através de ensino remoto? Para tanto, colocaremos em relevo discussões sobre o ensino de línguas enquanto um fenômeno complexo (LARSEN-FREEMAN, 1997), no prisma da Teoria da Complexidade (MORIN, 2003, 2005; BORGES; PAIVA, 2011), visando a busca de novas propostas para a situação atualmente experimentada.

Diante de tais premissas, objetivamos colocar em evidência algumas discussões dessa vivência em específico, a qual foi realizada por meio de atividades transdisciplinares aplicadas no formato de ensino remoto em turmas de $1^{\circ}, 2^{\circ}$ e $3^{\circ}$ anos do Ensino Médio, historicamente situados no contexto da Educação Básica da rede pública estadual, em tempos de pandemia causada pela Covid-19.

Para isso, situamo-nos nos pilares basilares da Linguística Aplicada (LA), que preza por uma abordagem de ensino crítica e contextualizada de acordo com a realidade de inserção dos sujeitos. Conforme assevera Signorini (2006, p. 186), isso exige "uma compreensão aprofundada de sua dimensão histórica, social e política", tratando-se, assim, de compreender o ensino de línguas dentro de um pensamento complexo que visa à formação do aluno de 
forma integral, considerando as multidimensionalidades envolvidas na prática docente e percebendo novas maneiras de aprendizagem.

Uma vez apresentadas as considerações iniciais deste estudo, discutiremos, a seguir, sobre os pilares teóricos que sustentam a pesquisa.

\section{O ensino de Língua Inglesa e a Teoria da Complexidade}

Devido ao vasto desenvolvimento técnico-científico experienciado nos últimos dois séculos, vivemos, atualmente, um momento marcado por profunda instabilidade econômica, fragilidade social e mudanças ambientais que ocorrem em todo o planeta. Apesar de todos os avanços advindos desses progressos tecnológicos e científicos, testemunhamos uma crise antropológica, epistemológica e paradigmática (MORIN, 2003, 2005; MORAES, 2012; BEHRENS, 2009), que afeta diretamente todos os setores da experiência humana, incluindo a área educacional e suas implicações metodológicas.

As antigas formas de aprender e ensinar ainda são baseadas em um modo cartesiano de fazer docência, o que nos leva a concordar com Weil (1991) quando anuncia que o paradigma newtoniano-cartesiano é o responsável pela fragmentação experienciada na atualidade, onde há uma supremacia da razão sobre a emoção, assim como uma multiplicação de infindáveis especializações.

Nesse paradigma, uma visão mecanicista de mundo impera e, segundo Moraes (2012, p. 74), "necessitamos de uma inteligência da complexidade mais condizente com a atual evolução da ciência e da problemática atual, no sentido de provocar transformações mais significativas, relevantes, oportunas e necessárias". Isso indica, todavia, uma necessidade de novos enfoques que sejam mais abrangentes e tenham maior profundidade, a fim de que ocorram mudanças e reconfigurações no sistema educacional, pois as práticas pedagógicas atuais ainda se baseiam no paradigma cartesiano.

Uma das questões abordadas por Behrens (1999) enfatiza as consequências dessa hiperespecialização do saber desencadeada pelo pensamento cartesiano na prática docente. Segundo a autora, o pensamento newtoniano-cartesiano propôs a fragmentação do todo e, consequentemente, as escolas repartiram o conhecimento em áreas, as áreas em cursos, os cursos em disciplinas e as disciplinas em especificidades. Behrens (1999, p. 384) reforça que:

A repartição foi tão contundente que levou os professores a realizarem um trabalho docente completamente isolados em suas salas de aula. Outro fator relevante de influência deste paradigma na ação docente é a busca da reprodução do conhecimento. Caracterizada pela fragmentação, a prática pedagógica propõe ações mecânicas aos alunos, provocando um ensino assentado no escute, leia, decore e repita. 
Diante desse contexto, Borges e Paiva (2011, p.341) asseveram que existe a necessidade de mudanças, entretanto, "uma revolução científica aos moldes das ciências humanas e sociais não se manifesta como um rompimento estrito com o que se fazia antes, mas se configura numa nova forma de olhar o objeto de estudo". Portanto, referente à disseminação da Teoria da Complexidade tanto na área da Linguística quanto em outras, como Administração, Comunicação e Informática, Paiva e Corrêa (2016, p. 397) apontam que é notável o crescente número de estudiosos que se dedicam a compreensão de seus objetos de estudo enxergando a dimensão do processo como um todo. Nesse processo são relevantes a observação, análise e discussão de elementos presentes no fluxo processual, dado que "aspectos periféricos na relação parte/todo, que mesmo não replicáveis, acabam por relevar domínios científicos antes pouco explorados quando tomados a partir de um recorte metodológico, exclusivamente, disciplinar" (PAIVA e CORRÊEA, 2016, p. 397). Tais afirmações denotam esse alerta para uma mudança de olhar para o objeto, a qual deve ocorrer, principalmente de forma não fragmentada.

Segundo essa vertente, entende-se a importância de que todas as considerações sejam feitas em nível sistêmico, pois como Paiva e Corrêa (2016) ressaltam, a Teoria da Complexidade na perspectiva dos Sistemas Adaptativos Complexos, a qual tem em suas origens a Química e a Física, são áreas do conhecimento científico que possibilitam que a Linguística explore a complexidade sob outros vieses, pois segundo os autores, a tensão gerada entre teorias distintas convoca os linguistas à proposição de novos construtos teóricos colaborando com um novo agir-pensar a Linguística.

Desse modo, na perspectiva da complexidade, tanto a linguagem como o ensino/aprendizagem são fenômenos igualmente complexos, que, de acordo com Borges e Paiva (2011, p. 344), a linguagem é um "processo bio-cognitivo, sócio-histórico e políticocultural", o que nos torna, portanto, seres de linguagem, pois "somos, nós mesmos, sistemas complexos que se auto-organizam para poder sobreviver como seres que usam a língua(gem) para pensar, comunicar e agir na interação com o meio e com nossos pares", pelo fato de nos caracterizarmos, também, como seres que aprendem e que mudam.

Vemos, assim, que boa parte da comunidade científica da área de Linguística Aplicada simpatiza com os fundamentos da Teoria do Caos/ Complexidade (Borges e Paiva, 2011), por ser uma forma de se pensar a complexidade existente na natureza da aquisição e do ensino/aprendizagem de línguas. Por conseguinte, nos domínios do paradigma da complexidade, se faz necessário apresentar uma nova visão de linguagem, o que significa formular 
uma visão mais ampla da natureza do ensino/aprendizagem, bem como enfatizar a complexidade subjacente à aquisição de segunda língua.

É consenso na literatura da área de Linguística Aplicada o fato de Diane Larsen-Freeman ter aberto os caminhos dos estudos da Teoria da Complexidade voltados para os processos de aquisição e aprendizagem de línguas, trazendo novas possibilidades e formulações teóricas no que tange aos Sistemas Adaptativos Complexos (PAIVA, 2005; LEFFA, 2009). De igual modo, Borges e Paiva (2011) apontam que, no contexto específico da Linguística Aplicada, Larsen-Freeman (1997) é a pioneira em se referir à aquisição de segunda língua como um fenômeno complexo.

A partir de então, o viés do pensamento complexo (MORIN, 2005) tem ganhado espaço nos estudos linguísticos, trazendo à tona a discussão das características dos sistemas adaptativos complexos, os quais são não-lineares, dinâmicos, imprevisíveis, fractais e abertos, dentre outras características. Nessa perspectiva, por intermédio do estudo de tais particularidades, podemos assim, tentar preencher certas lacunas teóricas na área de ensino de línguas, lacunas essas que outras abordagens teóricas ainda não puderam satisfazer.

\section{Ensino de línguas em tempos de covid-19 e a Complexidade}

Antes de tecermos comentários sobre a Complexidade na Educação em tempos de pandemia, cabe destacar a diferença que ocorre entre ensino remoto e Educação a Distância. A última se popularizou no cenário acadêmico com as Tecnologias da Informação e Comunicação (TICs), já o primeiro se notabilizou no contexto da pandemia da covid-19, em que várias instituições de ensino o adotaram para cumprir sua carga horária de ano letivo ou como uma alternativa para não deixar os alunos sem contato com os estudos ao longo do período de afastamento social.

A Educação a Distância (EaD) é uma modalidade de ensino presente na Lei de Diretrizes e Bases da Educação Nacional (LDB 93/96). No Brasil, a EaD encontra-se legitimada, também, pelo Decreto número 5.622 de 2005 que assevera:

\footnotetext{
Art. 1o Para os fins deste Decreto, caracteriza-se a Educação a Distância como modalidade educacional na qual a mediação didático-pedagógica nos processos de ensino e aprendizagem ocorre com a utilização de meios e tecnologias de informação e comunicação, com estudantes e professores desenvolvendo atividades educativas em lugares ou tempos diversos (BRASIL, 2005, p. 1).
}

Em outras palavras, a EaD tem se estabelecido no cenário educacional de forma bastante efetiva por oferecer oportunidades de acesso aos estudos de graduação, pós-graduação, 
entre outros, os quais só poderiam ser feitos por quem estivesse nos grandes centros ou em locais que permitiam essa realização de forma presencial.

Por outro lado, o ensino remoto ainda se encontra em caráter de uso emergencial, sendo, no momento, um recurso largamente utilizado por conta das implicações sociais causadas pela covid-19. Se na EaD contamos com ambientes virtuais de aprendizagem de interação predefinidos, por exemplo, o Moodle, o qual oportuniza o processo dialógico entre os cursistas, professores e tutores, no ensino remoto não podemos contar com um ambiente de aprendizagem fixo, acrescendo a isso o fato de apresentar poucas possiblidades para o diálogo e o trabalho colaborativo.

Com efeito, por conta da pandemia, ainda mais percalços se adicionaram a um cenário educacional em que já havia uma gama de obstáculos instaurados, pois a rede pública de ensino no Brasil vem apresentando desafios particulares em relação a questões organizacionais e estruturais há bastante tempo. Muito embora algumas questões tenham se tornado aparentemente intransponíveis devido ao agravamento de uma situação já delicada, como, por exemplo, a dificuldade de acesso às tecnologias digitais (as quais seriam um dos únicos meios de acesso aos estudos pelos alunos devido ao distanciamento social), evidenciou-se uma necessidade de se lançar um olhar para as possibilidades de fazer com que o ensino alcance o aluno e que o faça por meio de uma abordagem que estimule seu crescimento de forma plena.

Segundo Morin (2003), a inteligência que só sabe separar fragmenta o complexo do mundo em pedaços separados, fraciona os problemas e unidimensionaliza o que tem múltiplas dimensões, atrofiando, assim, as possibilidades de compreensão e reflexão de forma mais abrangente. Isso é, por sua vez, diametralmente oposto ao que se procura fazer em uma educação que visa o rompimento com fronteiras que limitam a expansão do ser enquanto indivíduo que se encontra em pleno desenvolvimento e emancipação. Desse modo, ainda segundo o autor, a fragmentação de saberes se mostra insuficiente para tratar nossos maiores problemas, pois:

\footnotetext{
[...] quanto mais os problemas se tornam multidimensionais, maior se torna a incapacidade de pensar sua multidimensionalidade; quanto mais a crise progride, mais progride a incapacidade de pensar a crise; quanto mais planetários tornamse os problemas, mais impensáveis eles se tornam. Uma inteligência incapaz de perceber o contexto e o complexo planetário fica cega, inconsciente e irresponsável (MORIN, 2003, p. 14-15).
}

No trecho citado acima, Morin exalta a necessidade de se olhar a educação enquanto um sistema complexo e interconectado com múltiplos fatores, ao invés de vê-la de forma contida e restrita. Suas palavras se encaixam muito bem na atual situação, na qual a educação sofre uma espécie de 'crise dentro da crise', pois em um cenário já permeado por dificuldades, 
a pandemia só veio a contribuir para um agravamento da situação em que se encontra a educação atualmente.

Morin (2002) aponta que um dos "buracos negros" da educação que não está sendo levado em consideração nos programas educacionais é exatamente a condição planetária. Em nosso contexto atual, vivemos em um mundo globalizado, no qual os seres humanos possuem uma ligação entre si, qual seja, um destino comum. Segundo ele, é necessário realizarmos uma educação direcionada para a compreensão de que vivemos em uma comunidade global, voltada para um único destino, para que essa educação seja fortalecedora desses vínculos existentes entre os seres humanos. Portanto, o momento pandêmico nos revela o quanto somos interdependentes em âmbito planetário e como nosso fazer educacional deve ser permeado dessa filosofia em termos de coletividade, em prol de uma busca por perspectivas diferentes para a educação.

Morin $(2003,2005)$ nos relembra, também, a imprescindibilidade de se pensar o sistema de ensino de forma a não isolar os objetos de seu meio ambiente, nem separar as disciplinas, para trabalhar-se em favor de um reconhecimento de suas correlações ao invés de dissociar os problemas. Ou seja, o autor questiona o treinamento que esse sistema educacional fragmentado realiza com as mentes jovens, dado que resulta na perda de suas aptidões naturais de contextualizar os saberes e os integrar em seus devidos conjuntos, quando justamente o contrário deveria estar sendo feito.

Portanto, o estímulo à capacidade de contextualizar e englobar, questionado por Morin (2003, 2005), nos remete à questão da importância do fomento a um pensamento reflexivo e questionador, o qual configura como um dos elementos centrais na formação e educação linguística (PENNYCOOK, 2001, 2004, 2012; JORDÃO, 2013, dentre outros). Essa importância é ressaltada dada a indispensabilidade de um ensino que contribua com uma forma de pensar menos compartimentada, sendo mais aberta, mais livre, para formar indivíduos autônomos e que nutram uma consciência em constante expansão, especialmente no atual momento pandêmico.

Passemos, agora, portanto, para a seção seguinte, na qual discutiremos sobre os aspectos metodológicos utilizados na pesquisa.

\section{Percursos metodológicos: relatando experiências}

O escopo metodológico deste estudo está situado nos arcabouços teóricos e metodológicos da Linguística Aplicada, enquadrado nos paradigmas qualitativos da pesquisa. Para Yin (2001, p. 69), “a metodologia pressupõe, em alguns casos, a existência de uma teoria 
prévia que será testada no decorrer da investigação e admite em outros casos a construção de uma teoria a partir dos achados da pesquisa". É nesse modo qualitativo de se fazer pesquisa que apresentamos nosso objeto de estudo, o ensino-aprendizagem de línguas em uma abordagem complexa.

Além de se situar no contexto qualitativo, este estudo possui inspiração etnográfica, pois conforme assevera Siqueira (2008, p. 37), a “"pesquisa etnográfica' ou 'etnografia' tem se destacado como um dos métodos qualitativos mais importantes da pesquisa social", tamanha sua relevância nesse contexto. Desse modo, por se tratar de um movimento em direção a um acesso no que tange ao entendimento de questões de ensino-aprendizagem de línguas, consideramos o caráter essencialmente social do objeto deste estudo.

Diante disso, apresentaremos, a seguir, a descrição do corpus de estudos. Assim que se iniciou a pandemia, houve uma reunião com todo o corpo administrativo e docente da escola estadual, situada no interior do estado, onde ocorreu a experiência, para serem discutidos os detalhes de como se daria o ensino a partir daquele instante em que era iniciado o distanciamento social. Em um primeiro momento, como a grande maioria dos alunos não tinha amplo acesso a dispositivos eletrônicos ou internet, foi-se decidido que seriam enviadas atividades de forma remota, ou seja, por arquivos em formato pdf, pelo whatsapp. Dessa maneira, o coordenador da escola manteve um grupo de whatsapp com cada turma da escola, e era ele o responsável por repassar as atividades para os alunos.

No entanto, os alunos que não tinham acesso a nenhum dispositivo eletrônico ou não podiam pedir a alguém que o tivesse para receber a atividade, procuravam a escola para receber a atividade de forma impressa. Nesse contexto, essa situação vai de encontro aos pensamentos de Leffa (2009, p. 22), ao pontuar que "o acesso a esses suportes linguísticos multimidiáticos, incluindo a internet, está se popularizando cada vez mais, chegando à periferia". Em outras palavras, os estudantes da escola em questão, como já foi mencionado, estão inseridos, em sua maioria, em comunidades da zona rural considerada com baixo poder aquisitivo. Isso representa que os aparatos tecnológicos estão longe de se tornarem realidade para esse público, pois o Brasil ainda é um país desigual socialmente.

As atividades eram enviadas semanalmente. Após algumas semanas, uma nova reunião foi realizada, na qual solicitamos a realiação de uma modificação: ao invés dos professores realizarem as atividades de forma isolada por disciplina, pedimos que elaborassem em conjunto com os outros professores de sua própria área. No nosso caso, as atividades foram, assim, realizadas em conjunto com os outros professores da área de Linguagens. Logo, as atividades eram elaboradas de forma colaborativa entre os professores das disciplinas de 
Língua Inglesa, Português, Educação Física e Redação. Geralmente o objetivo e o tema eram acordados por nós, professores, através do grupo de whatsapp, criado exclusivamente com o intento de discutir e opinar sobre questões do desenvolvimento da atividade a ser enviada.

A princípio, delineávamos os objetivos centrais, como: multiletramento, letramento crítico, letramento emocional, ou a realização de um enfoque social, cultural, político, econômico, artístico, dentre outros. Foram explorados vários recursos semióticos, o que viabilizava o trabalho com música, pinturas de artistas famosos, poesia, textos literários, textos retirados de blogs e sites, quadrinhos, charges, dentre diversos gêneros discursivos.

Tudo era explorado por todas as disciplinas da área de Linguagens ao mesmo tempo, realizando questões transdisciplinares. Outro ponto a ser destacado, é que sempre primamos pelo respeito ao momento delicado que estava sendo vivenciado, explorando questões de cunho psicológico e afetivo, além de sempre primar pelo incentivo ao pensamento crítico voltado para o que estava acontecendo global e localmente.

Após uma semana do envio da atividade, o gabarito era enviado para que os alunos pudessem ter um parâmetro para orientar ou adicionar uma nova visão às suas respostas.

Como um meio de nos inteirarmos sobre o que os alunos acharam dessas atividades e da abordagem utilizada pelo grupo de Linguagens, elaboramos um formulário eletrônico contendo questões abertas e fechadas para que pudessem expressar suas opiniões em relação à tal iniciativa, com a finalidade de termos um diálogo com os alunos, mesmo que de maneira virtual.

Diante disso, o processo de cotejamento de dados desta pesquisa compreende a aplicação de um questionário nos alunos, tendo os formulários do Google como espaço de uso para realizar essa pesquisa de opinião. Nesse sentido, o questionário apresenta cinco perguntas no total, quatro fechadas e uma aberta, para obtermos as impressões dos alunos sobre as atividades remotas das disciplinas de Linguagens. Frente ao exposto, a utilização do questionário nesse estudo é considerada um instrumento de "trabalho-filtro" (COELHO, 2011, p. 92), haja vista que, por meio das expressões relatadas pelos alunos, a partir das questões desse instrumento, alcançamos informações cruciais para o desenvolvimento do processo investigativo.

Nesse enquadramento, buscamos saber, primeiramente, o que os alunos acharam da ideia de unificar as disciplinas em uma atividade única. Foi perguntado, igualmente, se eles haviam gostado das atividades propostas. Outra questão levantada, foi sobre a forma com a qual eles conseguiram realizar as atividades: se isso ocorreu com facilidade, de forma moderada ou se as realizavam com dificuldade. Um outro ponto abordado, foi se o gabarito 
enviado os ajudou a entender qual era a melhor forma de responder as questões propostas e se essa ajuda tinha sido parcial, total ou inexistente. Por último, foi perguntado se havia sugestões de modificação das atividades para que o processo de aprendizagem ocorresse de forma mais otimizada.

Uma vez apresentado o percurso metodológico do texto, passamos para seção seguinte, na qual discutiremos os achados da pesquisa.

\section{Resultados e discussão}

As atividades elaboradas pelo grupo de professores da área de Linguagens da escola onde ocorreu a experiência aqui relatada seguiam uma abordagem consoante com a teoria da complexidade, o que significa que essa se afastava de um viés linear e conteudista. Ao contrário, o conteúdo era explorado da forma mais diluída e refratária possível, procurando-se instigar sempre o processo reflexivo de forma mais abrangente em relação a todos os possíveis fatores ligados a cada questão proposta, ou seja, de forma não-reducionista.

Outra característica dessa iniciativa foi a tentativa de aproximar-nos mais de um ensino humanista, considerando todas as implicações sociais, emocionais e psicológicas da ocasião vivida naquele período onde instituía-se um ensino remoto durante o distanciamento social.

Diante disso, os dados cotejados a partir do formulário contendo a pesquisa de opinião dos alunos são expostos a seguir de maneira descritiva e, logo mais, realizamos uma análise sintética dos pontos mais proeminentes, para uma melhor compreensão da situação de modo mais abrangente.

Iniciamos com a descrição dos dados obtidos da primeira questão, na qual foi solicitada aos alunos que respondessem o que eles haviam achado da reunião das diferentes disciplinas que compõem a área de Linguagens em uma atividade única. De acordo com as respostas, a maioria, a qual figurou como $44.6 \%$ dos alunos, afirmou ter ficado satisfeita com a junção das disciplinas. Enquanto isso, 39.3\% ficou apenas parcialmente satisfeito, e finalmente, obtivemos uma minoria de $16.1 \%$ demonstrando descontentamento com a forma de trabalho dos professores da área citada.

No que se refere à segunda questão do formulário da pesquisa de satisfação, foi questionado se eles gostaram das atividades propostas. Conforme respostas cotejadas, de forma majoritária, $73.2 \%$ demonstrou satisfação com as tarefas elaboradas pelos professores das disciplinas de forma unificada, sendo que a minoria, 26.8\% demonstrou resistência ao apontar que não gostou dessa maneira trabalhada. 
Já a questão três teve a finalidade de obter informações sobre a forma como eles conseguiram realizar as propostas de atividades. Apenas $7.1 \%$ as respondeu com facilidade, ao passo que $57.1 \%$ as concluiu as de forma moderada e um quantitativo de $35.7 \%$ afirmou ter realizado as atividades com dificuldade.

Dando prosseguimento as discussões, foi perguntado sobre o gabarito enviado posteriormente para que eles próprios fizessem suas correções, como oportunidade de refazer as questões que haviam errado, ou de entender melhor a atividade proposta. Frente a isso, os dados cotejados indicam que cerca de $25 \%$ respondeu que o gabarito ajudou bastante, $60.7 \%$ disse que auxiliou parcialmente e $14.3 \%$ apontou que não ajudou.

Por fim, na questão cinco foi colocada em relevo a possibilidade de diálogo mais amplo com os alunos, uma vez que a pergunta foi elaborada de forma aberta para que eles pudessem se expressar livremente, destacando se teriam alguma sugestão de modificação para melhorarmos a elaboração das propostas de atividades. Apenas $62.5 \%$ dos alunos respondeu à questão aberta. De acordo com o retorno dos alunos, a grande maioria optou por dizer que não tinha nenhuma mudança em mente ou que não mudaria nada, podendo as atividades permanecerem da mesma forma.

No entanto, alguns poucos disseram que era indiferente se mandássemos ou não atividades, demonstrando falta de interesse ou desvalorização dos estudos. Já outros disseram que não deveríamos nem enviar atividades, pois o momento que estamos vivendo é caótico e que os professores estavam preocupados com atividades em detrimento das outras coisas.

Ainda falando sobre as respostas abertas da questão sobre sugestão de modificações, alguns pediram para elaborar atividades mais fáceis, outros desejavam que as atividades fossem por disciplina e não por área, pois eles achavam ser melhor assim. Além disso, houve uma sugestão de termos aulas virtuais pelo aplicativo Google Meet, pelo menos uma vez por semana, já que dessa maneira o aluno esclareceria suas dúvidas com o professor e teria menos dificuldades em realizar as tarefas.

De todas as respostas colhidas, houve duas que se referiram a todas as atividades da escola em geral. Em uma delas, um aluno expressou seu repúdio a todas as atividades enviadas em tempos de pandemia, por estarmos vivenciando um momento delicado. Nessa sugestão, ele alegou a calamidade do momento que estamos vivenciando, reconhecendo que está difícil para todos, não só para eles, mas também para os professores e que o melhor seria não mandarmos nenhum tipo de atividade. Ele destacou que, no momento, está mais preocupado com a família, principalmente os que estão em grupos de risco, por esse grupo 
familiar estar precisando mais dele do que nunca. Sobretudo, foi categórico em relatar que atividades e escola vêm depois, ou seja, não são proridade.

Ainda em resposta à essa última questão aberta, um outro aluno confessa não querer responder à nenhuma das atividades enviadas pela escola, inclusive de outras disciplinas, por se sentir inseguro, insuficiente, traumatizado e com medo de não ter capacidade para realizar as atividades por conta própria.

Ao analisar esses dados, pudemos delinear com clareza a existência de 3 grupos de alunos, dotados de certas peculiaridades em comum. Estes grupos são descritos a seguir:

- O primeiro grupo corresponde àqueles alunos que aceitaram muito bem a proposta da atividade com a abordagem nos moldes da complexidade. Esse foi um grupo de peso, formado pela maioria, que pode ser confirmado através do grande número de alunos que aprovou a reunião das diferentes disciplinas de Linguagens em uma atividade única. Isso denota uma atitude de outorga e, até, de apoio à iniciativa da realização da abordagem complexa que se caracteriza de forma transdisciplinar. Houve uma outra questão que resultou na grande maioria respondendo positivamente quanto a ter gostado da atividade. Isso foi muito positivo, pois significou que esse número expressivo de alunos demonstrou abertura para algo que se direciona à inovação em sua maneira de interagir com o conhecimento, demonstrando que esses estudantes corroboram e validam a possibilidade de uma mudança de paradigma no ensino.

- $\quad$ O segundo grupo, corresponde àqueles que disseram estar apenas parcialmente satisfeitos com a unificação das atividades, que responderam às atividades de forma moderada, isto é, nem com tanta facilidade, nem com tanta dificuldade. Esse grupo também afirma que o gabarito auxiliou apenas parcialmente no entendimento das questões. O que pudemos depreender desse grupo é que, existe tanto um nível de aceitação quanto de resistência em relação à proposta da nova abordagem. Isso significa que há aceitação, embora, ao mesmo tempo, há ressalvas quanto à novidade. Em razão disso, há um certo nível de conflito ao se deparar com essa maneira diferente de aprendizado. Em uma leitura mais profunda, ousamos dizer que esses alunos se encontram à meia altura do caminho, mas ainda olham para trás, apegados, de certa forma, ao modo tradicional de se conceber o conhecimento e de vivenciar os processos de ensinar e aprender.

- Há, no terceiro grupo identificado, uma quantidade bem menor de alunos. No entanto, esse grupo rechaça a ideia da junção de disciplinas, da realização de atividades de forma transdisciplinar e complexa, ao passo que revela uma resistência à proposta de quebra paradigmática e nos leva a entender que, preferiam ter um direcionamento das atividades da 
forma tradicional, com limites bem definidos entre uma disciplina e outra. Esse grupo apresenta raízes mais profundas nas suas concepções sobre o que é o ensino-aprendizagem e como ele deve ser, segundo a mentalidade formada que possuem a esse respeito.

\section{Palavras finais}

Em um momento no qual vivenciamos uma crise pandêmica de proporções preocupantes, constatamos de forma empírica como a desordem torna-se algo pertinente para a produção de organização da vida humana. Testemunhamos, assim, como a sociedade tem reagido às circunstâncias que têm trazido mudança para a ordem estabelecida, gerando novos meios de organização entre os indivíduos. Morin (2011) estabelece isso como o princípio de relação ordem/desordem/organização, e é o que temos vivenciado: fenômenos desordenados contribuindo para a produção de fenômenos organizados, os quais favorecem o crescimento da ordem.

Decerto, o momento atual está embebido de caos e complexidade, abrindo possibilidades de reorganizações em todas as esferas da realidade humana. Percebemos, portanto, que uma abordagem de ensino em tempos complexos clamava, também, por um paradigma instituído da mesma natureza.

Enovelamos, assim, a Teoria da Complexidade ao ensino de línguas, destacando o quanto uma formação multidimensional e integral dos sujeitos perpassa por várias instâncias, como as sociais, históricas, políticas e culturais, sendo todas imbricadas e interrelacionadas, estando em constante movimento de retroalimentação.

Assim, experienciamos o ensino-aprendizagem por um viés complexo com alunos do Ensino Médio de uma escola pública, quando buscamos avaliar as possibilidades de alcance da abordagem da Teoria da Complexidade no que se refere aos pontos positivos que estão atravessados nesse sistema complexo e adaptativo de ensino em tempos de pandemia, configurado como ensino remoto emergencial.

$\mathrm{Na}$ experiência aqui relatada, o ensino de línguas em tempos de pandemia teve a oportunidade de se configurar enquanto um sistema complexo, assim como nós, seres humanos, tivemos, igualmente, a chance de nos adaptar e nos auto-organizar nesse processo interativo com o meio e com os pares.

Diante das descrições e análises de todo esse processo, destacamos que ao enviarmos atividades remotamente para os estudantes da escola em questão, tínhamos como uma das maiores preocupações enquanto corpo docente e dirigente da escola a manutenção do vínculo com os alunos em um momento no qual todos precisavam, necessariamente, cumprir o distanciamento social. Este vínculo não era exclusivamente pelo ensino e aprendizagem, mas, 
também, voltado para o empenho quanto à estabilidade psicológica e emocional deles, sendo essas atividades uma forma de nos mantermos próximos, embora estivéssemos fisicamente distantes.

Nesse ponto, acreditamos ter sido válido o esforço de tentarmos nos fazer presentes, mesmo que remotamente, pois visamos imprimir nessa forma de comunicação uma marca de cuidado e zelo, tanto com o bem-estar do aluno quanto com o ensino-aprendizagem, o qual não poderia cessar de tentar algo inovador e que fosse transformador em suas vidas.

Entendemos, igualmente, que com a iniciativa de unificar as atividades da área de Linguagens tentamos realizar um movimento que partia do campo teórico para o campo prático, mesmo que isso tenha causado uma certa sensação de ausência de controle, o que foi, por si só, um ponto positivo. De acordo com Morin (2006, p. 6) o pensamento simples tenta "controlar e dominar o mundo real", enquanto o ideal é complexificar o objeto, pois assim, estamos trilhando caminhos a favor de uma busca por novas possibilidades, embora fossem trilhas na incerteza.

Edgar Morin (2006) se reporta à Complexidade como uma palavra que traz em si uma grande carga semântica, indicando confusão, incerteza, desordem. Neste estudo, nos deparamos com algumas dessas demandas do complexo. Ao trazermos nossas inquietações quanto ao ensino durante o momento vivenciado nessa pandemia, aliado aos desafios propostos por ela e aos desafios já pré-existente na área de ensino de línguas, percebemos que realmente estamos em meio ao caos e a insegurança.

Assim, confirmamos as palavras de Morin (2006, p. 5-6) que nos relembram que não se pode fazer da complexidade algo que se defina de modo simples e que ocupe o lugar da simplicidade, pois "A complexidade é uma palavra-problema e não uma palavra-solução". Essa ideia é reforçada na presente discussão, pois trouxemos aqui um dilema vivenciado na educação atualmente, no qual tem se procurado encontrar meios de alcançar os alunos com um ensino problematizador, ao invés de simplificador, em um contexto totalmente novo.

Vimos assim, que pensar de forma complexa não é o fim de algo, propriamente dito, em termos de chegar-se a uma conclusão de maneira a encerrar-se um ciclo ou uma busca. Mas percebemos, claramente, que o pensamento complexo significa entender a incompletude do conhecimento (MORIN, 2006), pois exercemos a consciência de que, embora não conquistando desfechos mágicos ou fórmulas de sucesso absoluto, uma visão mais holística do cenário de forma geral foi despertada.

Se a Complexidade está totalmente relacionada com a práxis, com a ação que busca transformações, expansões e tomadas de consciência, vimos aqui, uma forma de demonstrar 
uma aplicação prática dessa em um momento extremamente oportuno, que vem exigindo novas abordagens para novos resultados, o que se relaciona ao que Morin (2006, p. 81) afirma quando diz que "a ação supõe a complexidade, isto é, acaso, imprevisto, iniciativa, decisão, consciência das derivas e transformações", relacionando, dessa forma, nossa investida de afastamento de um pensamento reducionista para caminhar em direção a algo complexo, e não por isso fácil, mas configurando uma ação em direção ao novo.

Desse modo, a atitude de direcionamento para o novo significou palmilhar caminhos desconhecidos, incertos, mas trouxe consigo a promessa de perspectivas diferentes e, possivelmente, um embasamento para novos olhares e novas abordagens sobre as formas de educar. Percebemos, igualmente, que resistências a um novo fazer pedagógico e metodológico podem ocorrer, mas que isso é previsível e até compreensível, pois toda novidade traz consigo a possibilidade de estranhamento, até que sejam mais exploradas e desenvolvidas as raízes de um trabalho potencialmente frutífero mais adiante.

Assim, uma das visões mais claras que obtivemos foi de que a proposta de um estímulo à uma visão mais abrangente de mundo, de forma mais crítica, mais reflexiva, mais cultural, mais diluída em relação aos seus conteúdos e interconectada com diversas esferas e disciplinas é um desafio não apenas para os professores, mas para os alunos, uma vez que, pensar "fora da caixa", ou seja, de maneira inovadora, holística, complexa, é algo que ainda é recebido com ressalvas por alguns, pelo fato de exigir que se saia do lugar comum ou da zona de conforto habitualmente familiar de outrora.

Como dito por Morin (2006, p. 8), "Se a complexidade não é a chave do mundo, mas o desafio a enfrentar, por sua vez o pensamento complexo não é o que evita ou suprime o desafio, mas o que ajuda a revelá-lo, e às vezes mesmo a superá-lo". E com ações pontuais como essas descritas aqui neste relato, podemos propor esse olhar de frente para os desafios, literalmente vis-à-vis, tentando não apenas o alcance de um desfecho para eles, mas o fato de simplesmente trazê-los à luz, já nos coloca a caminho de uma possível transformação.

Identificar três grupos de alunos com perfis diferentes de aceitação, adaptação e resistência à nova abordagem de ensino proposta preparou terreno para sabermos o que esperar dessa abordagem complexa na prática de nossas realidades diárias enquanto professores e aprendizes que somos do fazer-docência em meio a tempos novos, mas tempos esses que trazem consigo grandes perspectivas de futuras ações que promovam edificações ainda maiores e melhores na educação.

Destacamos, finalmente, que este estudo abre possibilidades de investigações mais ampliadas para produzir novos conhecimentos sobre o ensino de línguas atrelado à Teoria da 
Complexidade, dada a vastidão desse cenário. Como sugestão de futuras pesquisas, indicamos a questão da formação do professor e sua preparação para conduzir o ensino dentro de um pensamento complexo, para que, através deste suporte, ele se sinta preparado para a implementação dessa prática transdisciplinar do conhecimento, independentemente do contexto no qual ela possa vir a ocorrer.

Entendemos o quão importante são as considerações tecidas nos dias de hoje, derivadas da atual situação que vivenciamos nestes tempos quando andamos em terrenos ainda desconhecidos e, portanto, ainda de forma vacilante. Esperamos, assim, que essas mesmas considerações nos sirvam de referencial e nos guiem, de alguma maneira, rumo à uma (re)construção com maior solidez e plenitude dos cenários educacionais do mundo pós-pandêmico. E que, claro, esse mundo possa ser um mundo bem melhor.

\section{LANGUAGE TEACHING THROUGH A COMPLEX APPROACH IN TIMES OF PANDEMIC: BREAKING PARADIGMS}

ABSTRACT: The challenges triggered by the covid-19 pandemic that Education has faced globally have fostered reflections on new ways of teaching and learning in the school context. In this article, we expose the experience report of conducting language teaching within a complex approach, which took place in high school at a public school through remote education, in a context imbued with restrictions on internet access. The main objective of this study was to evaluate the possibilities of reaching this approach, as well as its positive points and the obstacles experienced. Through the analysis of this process, we conclude that it is possible to work with language effectively within a perspective of complexity, as it carries the benefits of multidimensional, nonlinear, non-reductionist and transdisciplinary teaching, which intends to encourage the critical capacity of the student, while working on historical, social, political, cultural and psycho-emotional factors, giving rise to a training focused on the integral individual, with activities that are appropriate to their current context and reality. As obstacles, we witnessed a certain resistance of some students to the complex teaching-learning paradigm. The paradigm proposed was part of a teaching process that was not fragmented in disciplines, and for having a greater range of scope and breadth in approaching the themes proposed in the activities it required a more questioning and reflective position from the student. A portion of these students still showed a certain feeling of attachment to a more Cartesian view of conceiving knowledge, being still rooted in the traditional teachinglearning processes.

KEYWORDS: Complexity; Integral formation; Language teaching; Remote teaching; Transdisciplinarity.

\section{REFERÊNCIAS}

ALMEIDA, M. C.; CARVALHO, E. A. (Orgs.). Edgar Morin. Educaşão e complexidade: "Os sete saberes" e outros ensaios. 5. ed. São Paulo: Cortez, 2009. 104 p.

BEHRENS, M. A. A prática pedagógica e o desafio do paradigma emergente. Revista Brasileira de Estudos Pedagógicos. Brasília, v. 80, n. 196, p. 383-403, set.-dez./1999.

BEHRENS, M. O paradigma emergente e a prática pedagógica. 3. ed. Petrópolis: Vozes, 2009.

BORGES, E. F. V.; PAIVA, V. L. M. O. Por uma abordagem complexa de ensino de línguas. Linguagem \& Ensino, Pelotas, v. 14, n. 2, p. 337-356, jul./dez. 2011.

BRASIL. Decreto 5.622, de 19 de dezembro de 2005. Diário Oficial [da] República Federativa do Brasil. Brasília, DF, 20 dez. 2005. Disponível em: < 
http://www.planalto.gov.br/ccivil_03/_ato2004-2006/2005/decreto/d5622.htm>. Acesso em: 28 out. 2020.

COELHO, F. C. B. de. Construção identitária e $(m)$ comportamentos na sala de aula: o agenciamento da palavra em dois grupos (um alemão, um brasileiro). 2001. 266 f. Tese (Doutorado em Linguística e Língua Portuguesa). Pontifícia Universidade Católica de Minas Gerais, Belo Horizonte, 2011.

LARSEN-FREEMAN, D. Chaos/Complexity Science and second language acquisition. Applied Linguistics, v. 18, n. 2, p. 141-165, 1997.

LEFFA, V. J. Se mudo o mundo muda: ensino de línguas sob a perspectiva do emergentismo. Calidoscópio, v. 7, n 1, p. 24-29, 2009a.

Por um ensino de idiomas mais includente no contexto social atual. In: LIMA, D. C. Ensino e aprendiragem de lingua inglesa: conversas com especialistas. São Paulo: Parábola Editorial, 2009b. p.113-123.

MORAES, M. C. Transdiciplinaridade e educação. In: MAGALHÃES, S. M. O; SOUZA, R. C. R. (Org.). Formação de professores: elos da dimensão complexa e transdisciplinar. Goiânia: Ed. da PUC Goiás, 2012, cap. 3, p. 73-90.

MORIN, E. Os sete saberes necessários à educação do futuro. Brasília: Cortez Unesco, 2002.

- A cabeça bem feita: repensar a reforma, reformar o pensamento. Rio de Janeiro: Bertrand Brasil, 2003. Introdução ao pensamento complexo. 4 ed. Porto Alegre: Sulina, 2011. Ciência com consciência. Rio de Janeiro: Bertrand Brasil, 2005. . Introdução ao pensamento complexo. Tradução de Eliane Lisboa. Porto Alegre: Sulina, 2006.

PAIVA, V. L. M. O. Modelo fractal de aquisição de línguas. In: BRUNO, F. C. (org.). Reflexão e prática em ensino/ aprendizagem de lingua estrangeira. São Paulo, Editora Clara Luz, 2005, p. 23-36.

PAIVA, V. L. M. O.; CORREAA, Y. Sistemas Adaptativos Complexos: uma entrevista com Vera Lúcia Menezes de Oliveira e Paiva. ReVEL, v. 14, n. 27, 2016.

SIGNORINI, I. A questão da língua legítima na sociedade democrática um desafio para a linguística aplicada contemporânea. In: MOITA LOPES, L. P. da (Org.). Por uma linguística aplicada (in)disciplinar. São Paulo: Parábola Editorial, 2006, p.169-190.

SIQUEIRA, D. S. Inglês como lingua internacional: por uma pedagogia intercultural crítica. 2008. Tese (Doutorado em Letras e Linguística). Universidade Federal da Bahia, 2008. WEIL, P. O novo paradigma holístico: ondas a procura do mar. In: BRANDÃO, D.; CREMA, R. (Orgs). O novo paradigma holístico: ciência, filosofia, arte e mística. São Paulo: Summus, 1991. p. 14-38.

YIN, R. K. Estudo de caso - planejamento e métodos. 2.ed. Porto Alegre: Bookman, 2001.

Recebido em: 15/11/2020.

Aprovado em: 17/12/2020. 